\title{
LANDSLIDE SUSCEPTIBILITY MAPPING IN THE MUNICIPALITY OF OUDKA, NORTHERN MOROCCO : A COMPARISON BETWEEN LOGISTIC REGRESSION AND ARTIFICIAL NEURAL NETWORKS MODELS
}

\author{
S. Benchelha ${ }^{1}$, H. Chennaoui Aoudjehane ${ }^{1}$, M. Hakdaoui ${ }^{2}$, R.El Hamdouni ${ }^{3}$, H. Mansouri ${ }^{4}$, T. Benchelha ${ }^{1}$ \\ , M.Layelmam ${ }^{5}$, M. Alaoui ${ }^{6}$ \\ (1) GAIA Laboratory, Hassan II University of Casablanca, Faculty of Sciences Aïn Chock, Morocco. \\ (E-mail: said1.benchelha@gmail.com) \\ ${ }^{(2)}$ LGAGE Laboratory, Hassan II University of Casablanca, Faculty of Sciences Ben M'sik, Morocco. \\ ${ }^{(3)}$ Civil Engineering Department. Granada University, Granada, Spain \\ (4) Laboratoire Public d'Essai et d'Etudes (LPEE). Casablanca. Morocco. \\ (5) Hassan II Agronomic and Veterinary Institute, Rabat, Morocco. \\ (6) Laboratory of Management and Valorization of Natural Resources, Faculty of Science and Technology, \\ Sultan Moulay Slimane University, Beni Mellal, Morocco.
}

KEY WORDS: Landslide susceptibility mapping, regression logistic, Artificial Neural Networks, Oudka, Taounate

\begin{abstract}
:
The Rif is among the areas of Morocco most susceptible to landslides, because of the existence of relatively young reliefs marked by a very important dynamics compared to other regions. These landslides are one of the most serious problems on many levels: social, economic and environmental. The increase in the frequency and impact of landslides over the past decade has demonstrated the need for an in-depth study of these phenomena, allowing the identification of areas susceptible to landslides.

The main objective of this study is to identify the optimal method for the mapping of the area susceptible to landslides in municipality of Oudka. This area has been marked by the largest landslide in the region, caused by heavy rainfall in 2013. Two Statistical Methods i) Regression Logistics (LR) ii) Artificial Neural Networks (ANN), were used to create a landslide susceptibility map. The realization of this susceptibility map required, first, the mapping of old landslides by the aerial photography, the data of the geological map and by the data obtained using field surveys using GPS. A total of 105 landslides were mapped from these various sources. $50 \%$ of this database was used for model building and 50\% for validation. Eight independent landslide factors are exploited to detect the most sensitive areas: altitude, slope, aspect, distance of faults, distance streams, distance from roads, lithology and vegetation index ( NDVI).

The results of the landslide susceptibility analysis were verified using success and prediction rates. The success rate $(\mathrm{AUC}=0.918)$ and the prediction rate $(\mathrm{AUC}=0.901)$ of the LR model is higher than that of the ANN model (success rate $($ AUC $=0.886)$ and prediction rate $(\mathrm{AUC}=0.877))$.

These results indicate that the Regression Logistic (LR) model is the best model for determining landslide susceptibility in the study area.
\end{abstract}

\section{INTRODUCTION}

Landslides are considered to be the most common geological disaster, causing loss of human life and damage to the economy (Bui et al., 2012; Shahabi et al., 2014). This phenomenon occurs when natural or man-made slopes become unstable due to geological, hydrological and geomorphological conditions, heavy rainfall, seismic movements, volcanic eruptions, and human activities leading to destabilization of slopes (Soeters and van Westen 1996; Tasoglu, Citiroglu, and Mekik 2016), (Bai et al. 2014).

In Morocco, landslides are a recurrent problem throughout most of the Rif and to a lesser extent the Middle Atlas. This region exhibits mountainous topographical features, and is frequently subjected to heavy precipitation. This dynamic associated with the formation of the Rif chain (Alpine tectonics) is accompanied by instabilities mainly related to tectonic movements. The construction of major infrastructures (roads, highways, etc.) is a triggering factor and favors landslides. The latter causes many economic losses affecting populations, infrastructure and other goods.
To remedy this, it is necessary to predict areas that are susceptible to landslides. For the analysis of the susceptibility to landslides in the municipality of oudka, two models were applied and verified logistic regression and artificial neural networks for the study area of oudka, Taounate. The Geographic Information System (GIS) software such as R Studio and ArcGIS Software have been used for spatial data management and models building.

Several susceptibility studies have been applied using the different models : frequency ratio (Lee and Pradhan 2007; Umar et al. 2014; Hong et al. 2016b), weights of evidence ( Pourghasemi et al. 2012a, 2012b ), the logistic regression model ( Xu et al 2012b; Devkota et al. 2013; Park et al. 2013), support vector machine (SVM) (Yilmaz 2010 b; Peng et al. 2014; Tien Bui et al. 2015; Hong et al. 2016b), fuzzy logic (Akgun et al. 2012; Sharma et al. 2013; Zhu et al. 2014; Shahabi et al. 2015), decision tree (Nefeslioglu et al. 2010; Tien Bui et al. 2012; Hong et al. 2015) and Artificial Neural Network (ANN) ( Zare et al. 2013; Nourani et al. 2014; Nefeslioglu et al. 2008; Poudyal et al. 2010; Tien Bui et al. 2015; Dou et al. 2015). 
The Logistic Regression (BLR) and Artificial Neural Network (ANN) methods are considered to be the two most commonly used methods for assessing the probability of landslide occurrence at the mean and regional scales (Dou et al., 2018). In our study area, none landslide susceptibility studies were applied using Logistic Regression and Artificial Neural Network models.

In this context, this study aims at the realization of the landslide susceptibility maps using logistic regression and Artificial neural network models and based on 8 factors : topographic, hydrologic, land used, geology and human activity. The Validation, analysis and verification of these maps was performed using the Relative operative Characteristic curve (ROC) including success and prediction rates.

\section{STUDY AREA}

The study area is located in the north of Morocco, in the northwest of the province of Taounate, it is one of the areas most exposed to landslides in Morocco. The commune of Oudka is situated between the longitudes $4^{\circ} 42^{\prime} 11.40$ "W and 4 $\circ 56 ' 53.70^{\prime \prime} \mathrm{W}$ and the latitudes $34^{\circ} 42^{\prime} 35.05$ "N and $34^{\circ}$ $42^{\prime} 52.43$ " N, it covers a surface of $89 \mathrm{Km}^{2}$ (Fig. 1). This area is a continuation of the chain of the Rif is characterized by mountainous terrain with no plains except near the wadi Aoulai along the western boundary of the town. Jbel Oudka is considered the most important mountain of the province of Taounate, its altitude reaches $1600 \mathrm{~m}$. This mountain is characterized by a very important vegetal cover such as the Oudka forest. In the commune of Oudka, the olive tree occupies most of the arboreal surface area (92\%). It is followed by the cultivation of Fig and other crops. The municipality of Oudka is known at the national level by the importance of rainfall. Between 1977 and 2018, the Jbel Oudka station recorded an average annual rainfall of $1455 \mathrm{~mm}$. The territory of the commune Oudka is part of the producing area of the Ouergha watershed, it is crossed by several affluents of the oued Aoulai such as oued Elil oued Elmaleh and oued Assenou. Several lacs are identified in this territory and especially in the Oudka forest. the most important of them is Afrat N'joum which is located in the north of the Oudka and which has an area of $13000 \mathrm{~m}^{2}$.

The average annual temperature in the region is between $15^{\circ}$ and $16^{\circ} \mathrm{C}$. The average maximum temperature of the hottest month is around $34.2^{\circ} \mathrm{C}$ and the average minimum of the coldest month is $0.5^{\circ} \mathrm{C}$. The average extreme thermal amplitude is in the whole pre-rifaine area between $30^{\circ}$ and 32 ${ }^{\circ}$, which corresponds to a semi-continental climate.
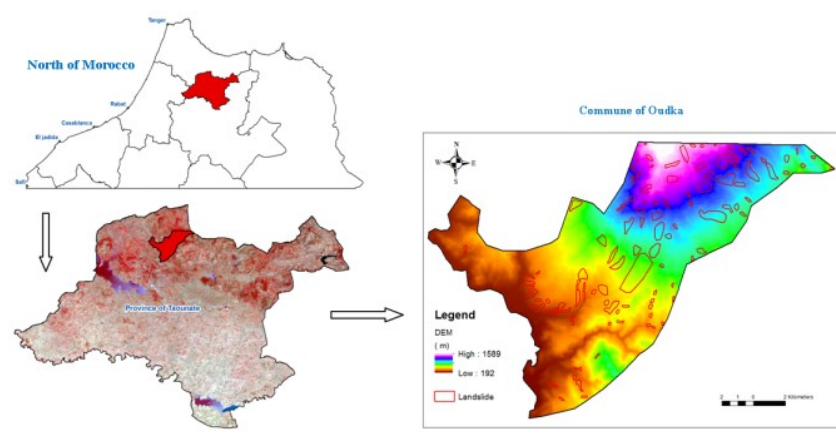

Fig.1 : Geographical location and distribution of landslide in Commune Oudka, Taounate Prefecture, Morocco

\section{SPATIAL DATABASE CONSTRUCTION}

\subsection{Image data}

Image Landsat OLI8 was downloaded from USGS web page and pre-processed by layer stacking of bands 2,3,4,5,6 and 7 . Landsat imagery that was collected along the same satellite path have been mosaicing into a single image. However, atmospheric correction was not necessary for images taken on the same calendar date (Song, Lee, and Seto 2001).

\subsection{Landslide inventory map}

In our study area, old landslide mapping data were obtained from: field surveys using GPS, geological map data, and Landsat oli 8 image processing data.

Several studies have shown that the best calculation model is one in which the ratio of landslides to non-landslide points is equal to 1 (Bai et al. 2010). A total of 105 field polygons and 43 randomly sampled polygons of the stable surface mapped from different sources were transformed into 8911 cells with a resolution of $30 \mathrm{~m}$ for landslide areas and 9005 cells for stable areas (without landslide). The 8911 cells of the landslide grid and the 9005 cells of the stable zone (without landslide) were randomly divided using the software $\mathrm{R}$ into two subsets: half of the cells of the grid were used for the realization of the landslide susceptibility model, while the other half was used for the validation of the model.

\subsection{Conditioning factor data set preparation}

In this study, we divided the conditioning factors into five datasets, including topographic, hydrologic, land used, geology and human activity datasets. The landslide conditioning factors from these datasets were extracted from different sources and stored in the spatial database using a spatial analysis tool (ArcGIS software) with a pixel size of $30 \mathrm{~m}$. 


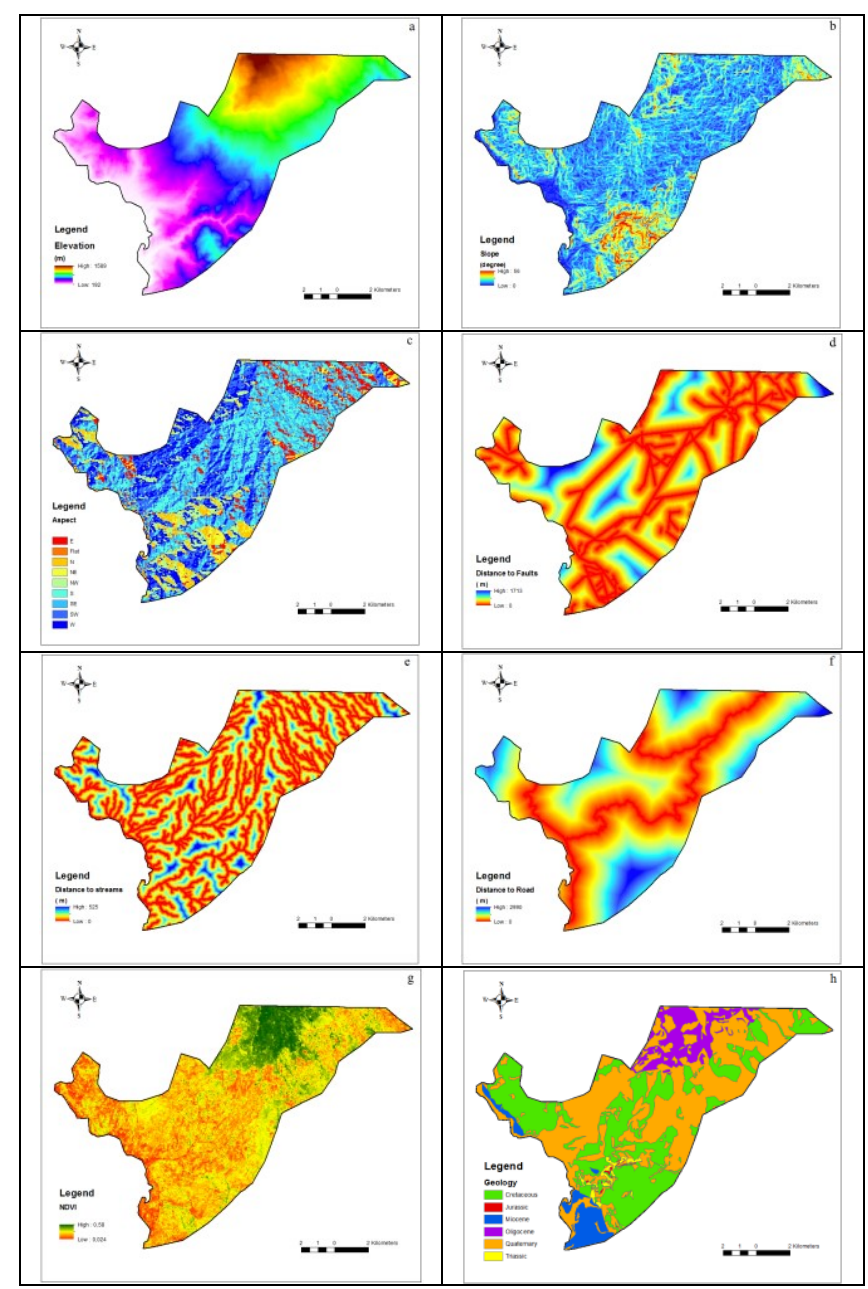

Fig.2 : Maps of some landslide conditioning factors: (a) elevation; (b) slope angle; (c) aspect; (d) distance to faults; (e) distance to streams; (f) distance to road; (g) NDVI; (h) Geology.

The topographical parameters, derived from the DEM model, such as: i) Elevation that is a conditioning factor, the values of this factor vary between 192 and $1600 \mathrm{~m}$, divided into ten classes: $<=350 \mathrm{~m}, 350-450 \mathrm{~m}, 450-550 \mathrm{~m}, 550-650 \mathrm{~m}, 650-750$ $\mathrm{m}, 750-850 \mathrm{~m}, 850-950 \mathrm{~m}, 950-1100 \mathrm{~m}, 1100-1300 \mathrm{~m}$ and $>$ $1300 \mathrm{~m}$ (Fig. 2a). ii) Slope is one of the key factors of slope stability, divided into ten classes: $\angle=5^{\circ}, 5^{\circ}$ to $10^{\circ}, 10^{\circ}$ to 15 $\circ, 15^{\circ}$ to $20^{\circ}, 20^{\circ}-25^{\circ}, 25^{\circ}-30^{\circ}, 30^{\circ}-35^{\circ}, 35^{\circ}-40^{\circ}, 40$ $\circ-45^{\circ}$ and $>45^{\circ}$ (Fig. 2b). iii) Aspect is considered to be one of the main factors in landslide conditioning in terms of landslide sensitivity, this factor has been divided into nine classes (Fig. 2c): Flat, North, North-East, East, South-East, South, South-West, West and North-West.

The hydrological parameter, such as the distance of streams, derived from DEM. this factor has been divided into ten classes (Fig. 2e): $<50 \mathrm{~m}, 50-100 \mathrm{~m}, 100-150 \mathrm{~m}, 150-200 \mathrm{~m}, 200-250 \mathrm{~m}$, $250-300 \mathrm{~m}, 300-350 \mathrm{~m}, 350-400 \mathrm{~m}, 400-450 \mathrm{~m}$ and $>450 \mathrm{~m}$.

The land use parameter used is the standardized difference vegetation index NDVI, derived from the Landsat OLI8 image. This factor has been subdivided into ten categories (Fig. $2 \mathrm{~g}$ ): $<=$ $0.1,0.10-0.15,0.15-0.20,0.20-0.25,0.25-0,30,0.30-0.35$, $0.35-0.40,0.40-0.45 ., 0.45-0.50$ and $>0.50$.

The distance-road parameter reflects the influence of human activities, extracting from a high-resolution image, it has been classified into ten classes (Fig. 2f): $<=250,250-500 \mathrm{~m}, 500$ -
$750 \mathrm{~m}, 750-1000 \mathrm{~m}, 1000-1250 \mathrm{~m}, 1250-1500 \mathrm{~m}, 1500-1750 \mathrm{~m}$ $1750-2000 \mathrm{~m}, 2000-2250 \mathrm{~m}$ and $>2250 \mathrm{~m}$.

The geological parameters, extracted from the Rhafsai geological map of the study area at 1: 50,000 scale, such as: i) The fault distance was calculated using the ArcGIS software and divided into ten classes (Fig. 2d): $<=150,150-300 \mathrm{~m}, 300-$ $450 \mathrm{~m}, 450-600 \mathrm{~m}, 600-750 \mathrm{~m}, 750-900 \mathrm{~m}, 900-1050 \mathrm{~m}, 1050-$ $1200 \mathrm{~m}, 1200-1350 \mathrm{~m}$ and $>1350 \mathrm{~m}$. ii) The lithology was digitized using the ArcGIS software (Fig. 2h) and was divided into six categories (Tab.1): Quaternary, Miocene, Oligocene, Cretaceous, Jurassic and Triassic.

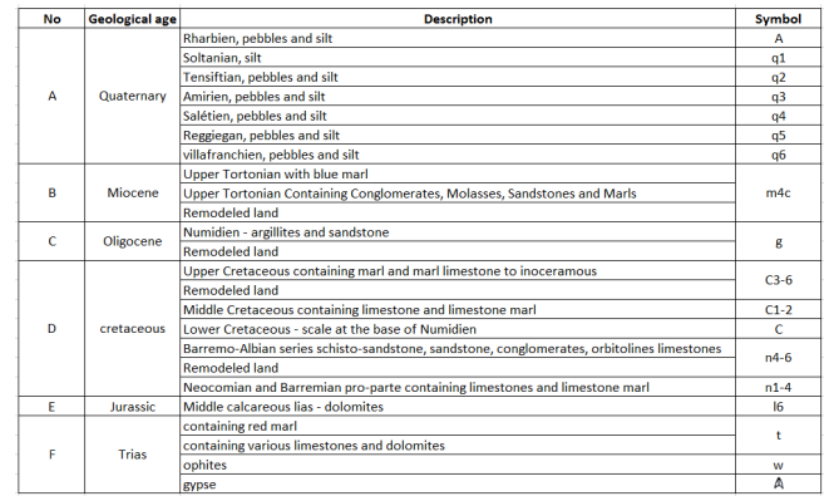

Tab.1 : Description of geological units of the study area

The resulting map contains categorical data that is transformed into numerical data to lighten the model (S. -B. Bai et al. 2010). We applied, the frequency ratio (FR) that is represented by the formula :

$$
F R=\frac{D_{i} / A_{i}}{\sum_{i=1}^{N} D_{i} / \sum_{i=1}^{N} A_{i}}
$$

Here $\mathrm{Di}$ is the area of a landslide of the $\mathrm{i}$-th category, Ai is the area of the i-th category for a given parameter, and $\mathrm{N}$ is the category number of the parameter.

The different geological components of the Oudka commune with their frequency ratio values can be found in Tab. 2 .

\begin{tabular}{|c|l|c|c|c|c|c|}
\hline Factor & \multicolumn{1}{|c|}{ Class } & $\begin{array}{c}\text { study area } \\
\text { (points) }\end{array}$ & $\begin{array}{c}\text { Percent of } \\
\text { class \% }\end{array}$ & $\begin{array}{c}\text { Landslide } \\
\text { points }\end{array}$ & $\begin{array}{c}\text { \% area cover by } \\
\text { landslide in each class }\end{array}$ & $\begin{array}{c}\text { Landslide } \\
\text { frequency \% }\end{array}$ \\
\hline \multirow{6}{*}{ Geology } & Quaternary & 47968 & 48,780 & 7012 & 78,689 & 1,613 \\
\cline { 2 - 7 } & Miocene & 5154 & 5,241 & 80 & 0,898 & 0,171 \\
\cline { 2 - 7 } & Oligocene & 8000 & 8,135 & 1 & 0,011 & 0,001 \\
\cline { 2 - 7 } & cretaceous & 35663 & 36,267 & 1816 & 20,379 & 0,562 \\
\cline { 2 - 7 } & Jurassic & 255 & 0,259 & 1 & 0,011 & 0,043 \\
\cline { 2 - 7 } & Trias & 1295 & 1,317 & 1 & 0,011 & 0,009 \\
\hline
\end{tabular}

Tab.2 : Frequency ratio values of the different geological components of the Oudka 


\section{METHODOLOGY}

Figure 3 presents a diagram illustrating the methodology used. For the application and verification of landslide sensitivity models, the study area was randomly divided into two parts, the first for model establishment and the second for validation. Areas of occurrence of landslides were detected in the study area by aerial photography, geological map data, and data obtained using GPS field surveys.

The Topographic, hydrologic, land use, geology and human activity databases were constructed for the analysis. From these databases, 8 factors were extracted. Using the landslides detected and the factors calculated or extracted, two methods of landslide analysis were applied: logistic regression and artificial neural networks. For the application of these, the R Studio software has been used. Finally, the results of the analysis were verified using the Relative Functional Characteristic (ROC) curve, including success and prediction rates (van Westen, Rengers and Soeters, 2003).

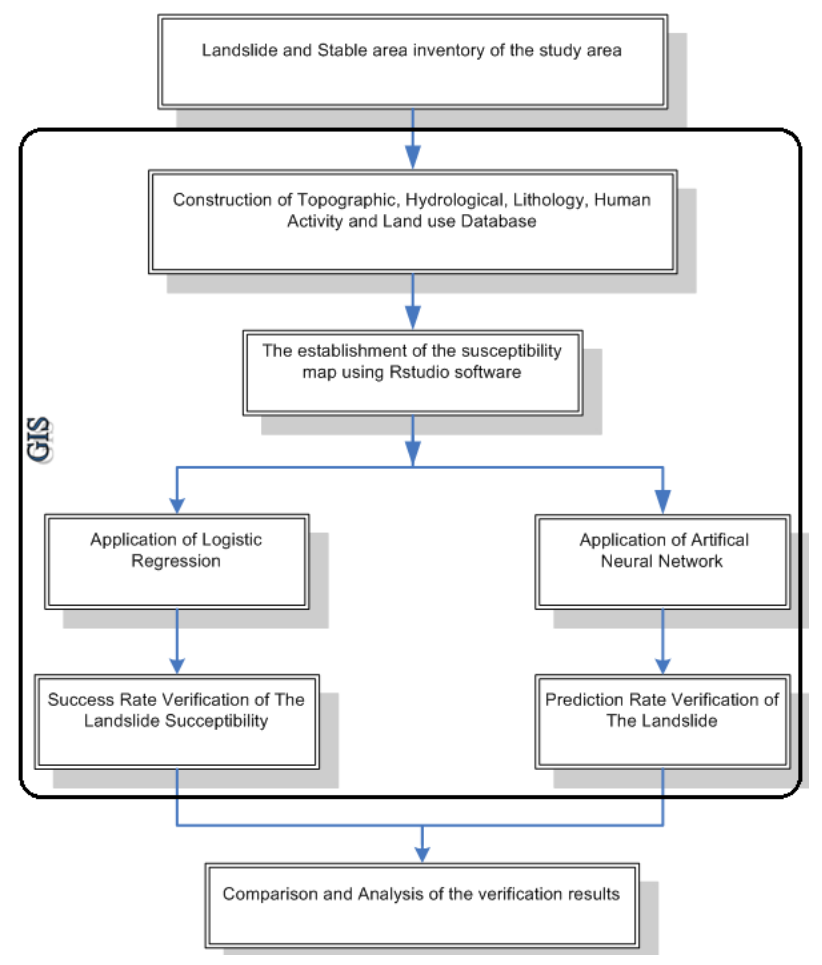

Fig.3 : Flow diagram showing the methodology

\section{LANDSLIDE SUSCEPTIBILITY MAPPING}

\subsection{Logistic regression model}

The logistic regression (LR) model is a mathematical method to establish the relationship between independent factors and landslides (Bai et al. 2010; Das et al. 2010; Nandi and Shakoor 2010). It's useful for predicting the presence or absence of a characteristic or outcome based on values of a set of predictor variables. Past studies compared logistic regression to support vector machines, classification trees and likelihood ratios and found that logistic regression was more accurate (Nandi and Shakoor 2010; Atkinson and Massari 2011; Demir, Aytekin, and Akgun 2015 ; Shahabi et al. 2014). Therefore, a common logistic-regression model has been used for landslide susceptibility mapping. The predicted values range from 0 to 1 and can be defined by the following equations:

$$
P(Y=1 / X)=\frac{1}{1+e^{-C(X)}}
$$

$$
\text { When : } C(X)=b 0+b 1 X 1+b 2 X 2+\ldots+b n X n
$$

where $\mathrm{P}$ is the probability of landslide occurrence (landslide susceptibility index), $\mathrm{C}(\mathrm{X})$ is the linear logistic model, b0 is the intercept of the model, $\mathrm{n}$ is the number of landslideconditioning factors, bi is the weight of the each factor, and $x i$ is the landslide conditioning factor.

The probability that predicts the possibility of landslide occurrence, for the study area, was calculated using a spatial database :

$$
P(Y=1 / X)=\frac{1}{1+e^{-C(X)}}
$$

( $\mathrm{p}$ is the probability of landslide occurrence)

\subsection{Artificial neural network model}

An ANN is a computational mechanism that can acquire, represent, and compute a map of information from one multivariate space to another using a data set representing that mapping. The purpose of an ANN is to build a model of the data-generating process so that the network can generalize and predict outputs from inputs that it has not previously seen (Lee, Ryu, and Kim 2007). The multi-layer perceptron (MLP) neural network, which has been described by (Rumelhart and Mcclelland 1986), is one of the most widely used ANNs. The MLP consists of three layers (input, hidden, and output layers) and can identify relationships that are non-linear in nature (Pijanowski et al. 2002). The MLP networks are trained by error-correction learning, which means that the desired response of the system must be known; a back-propagation (BP) algorithm must also be known. The S-shaped sigmoid function is a particular case of logistic regression used as the transfer function. The collective effect on each of the hidden nodes is summarized by performing the scalar product of all the values of the input nodes and their corresponding interconnect weights. Once the net effect on a hidden node is determined, activation on that node is calculated using a transfer function (sigmoidal function) to obtain a result between 0 and 1 .

The BP algorithm randomly selects the initial weights. Then, the difference between the expected and calculated output values across all observations is summarized using the meansquare error. After all observations are presented to the network, the weights are modified according to a generalized delta rule (Rumelhart and Mcclelland 1986). This process of feeding forward signals and back-propagating errors is repeated iteratively until the error stabilizes at a low level (Pijanowski et al. 2002)

\subsection{Results of landslide susceptibility models}

The database containing a dependent variable (landslide) and the eight independent variables (Altitude, Slope, Aspect, distance to faults, distance to streams, distance to the road, NDVI, Geology) were randomly divided into two parts the first to create models and the second for the validation using the $\mathrm{R}$ software.

In the case of the LR model, the multicollinearity should be checked. To quantify multicollinearity, there are several 
methods such as : Pearson's correlation coefficients (Booth et al.1994), variance decomposition proportions (Schuerman, 1983), conditional index (Belsley 1991), Variance Inflation (VIF) and Tolerances (Hair et al., 2009, Liao and Valliant, 2012).

In our case, the variance inflation factor (VIF) was used. The resulting values of VIF, as shown in the following table (Tab. 3 ), are all less than 4 , indicating that there is no colinearity problem to explore. in cases where landslide factors had a VIF value greater than 4 , these factors will not be applied to the logistic regression model.

\begin{tabular}{|l|c|}
\hline \multicolumn{1}{|c|}{ Factors } & VIF \\
\hline Elevation & 2.0219 \\
\hline Slope & 1.1242 \\
\hline Dist_fault & 1.1312 \\
\hline Dist_streams & 1.0983 \\
\hline Dist_road & 1.1296 \\
\hline Aspect & 1.1667 \\
\hline Geology & 1.1745 \\
\hline NDVI & 1.8110 \\
\hline
\end{tabular}

Tab.3 : Multicollinearity diagnosis indexes for independent variables

To evaluate the effectiveness of the training datasets, the Hosmer and Lemeshow test was used and gave in the Logistic Regression (LR) model being statistically significant and predictive.

The relationship between conditioning factors and landslides based on logistic regression (LR) is illustrated in Tab. 4.

\begin{tabular}{|l|c|}
\hline \multicolumn{1}{|c|}{ Parameters } & $\begin{array}{c}\text { LR model } \\
\text { coefficients }\end{array}$ \\
\hline Elevation & 0.003 \\
\hline Slope & 0.004 \\
\hline Distance to fault & -0.002 \\
\hline Distance to streams & -0.005 \\
\hline Distance to road & 0.0002 \\
\hline Aspect & 0.005 \\
\hline Geology & 3 \\
\hline NDVI & -2.314 \\
\hline Constant & -6.002 \\
\hline
\end{tabular}

Tab.4 : Coefficients of the LR model

From Table 4, the Distance to Fault, Distance to Streams and NDVI are negatively related to landslide risk, ie when the values of these factors increases the risk of landslides decreases. the landslide susceptibility map has been realized (Fig.4), based of the weights indicated in table 4 . the area of risk very high it is the area where there is a high probability $(\mathrm{P}>0.8)$ to have a landslide.

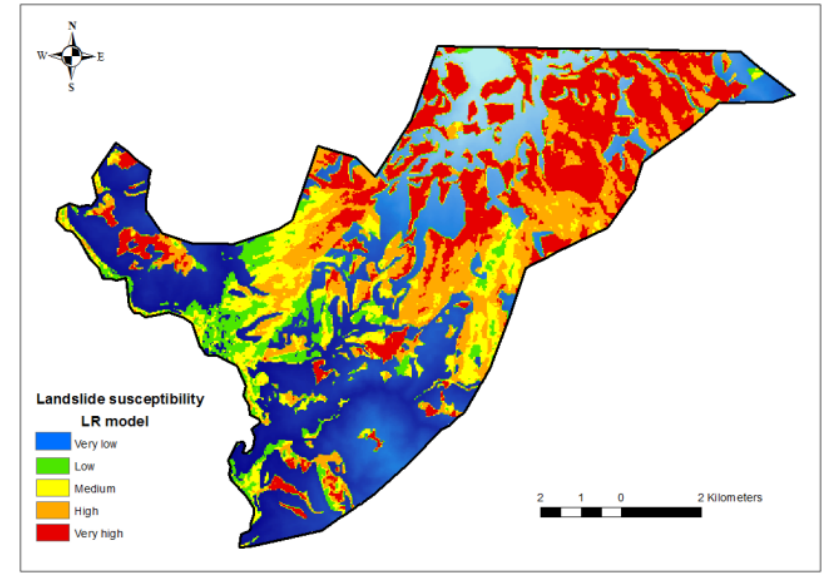

Fig.4 : Landslide susceptibility map produced from LR model.

Compared to statistical methods, the neural networks make it possible to define classes taking into account their distribution in the corresponding domain of each data source (Zhou 1999). After integrating the training data (dependent and independent) in the Multilayer Perceptron Neural Network (MLP) model using the $\mathrm{R}$ software, a network architecture was constructed consisting of eight neurons in the input layer, four and two neurons for hidden layers and a neuron for the output layer (Fig. $5)$.

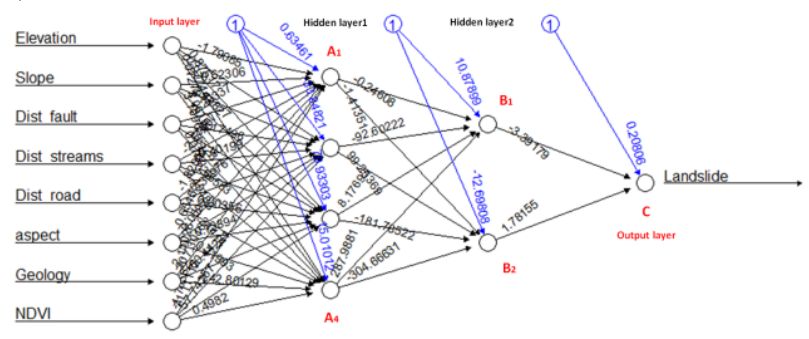

Fig.5 : Neural network architecture

The final weights edit and biases are shown in the following table (Tab.5):

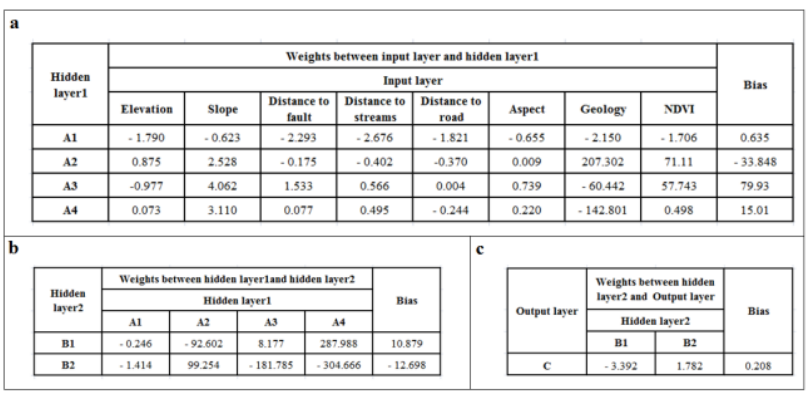

Tab.5 : The value of the weights and biases of the neural network model : (a) between input layer and hidden layer1, (b) between hidden layer1 and hidden layer2, (c) ) between hidden layer2 and output layer.

After completion of the learning phase (training and testing phases) and reaching the network objective, the data from the study area were introduced into the network to estimate landslide susceptibility.

After obtaining susceptibility values, the final map of landslide sensitivity was produced (Fig. 6). The area of risk very high it is the area where there is a high probability $(\mathrm{P}>0.8)$ to have a landslide. 


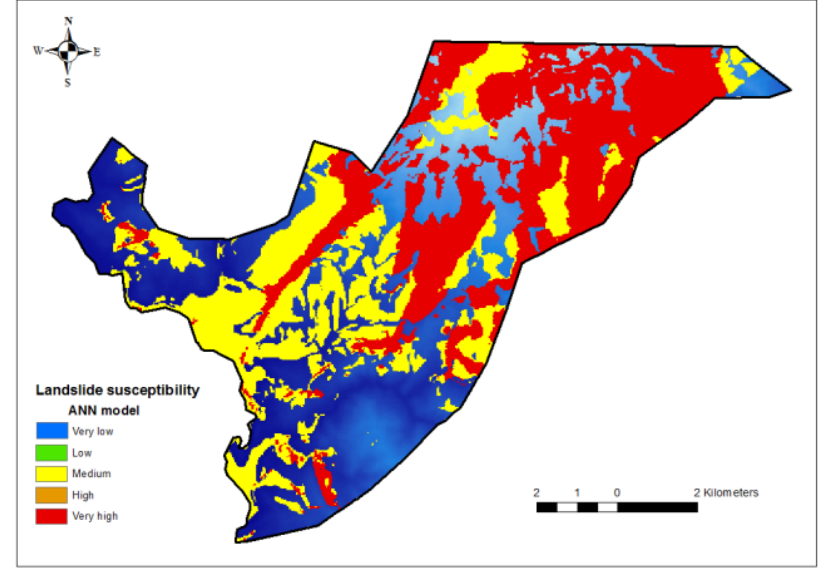

Fig.6 : Landslide susceptibility map produced from Artificial neural network model.

\section{VALIDATION AND COMPARISON}

The landslide susceptibility maps resulting from the use of the different statistical models (Logistic regression, and artificial neural network) were divided into five classes. The accuracy of these landslide susceptibility maps was evaluated by calculating the relative operating characteristic (ROC) and the percentage of landslide points observed in various susceptibility categories (Nandi and Shakoor 2010).

The area under the ROC curve (AUC) represents the quality of the probabilistic model (its ability to predict the occurrence or not of an event) (Yesilnacar and Topal 2005).

The ideal model shows a curve that has the largest AUC, AUC ranges between 0.5 and 1 . If the value of AUC is close to 0.5 indicates inaccuracy (Fawcett 2006).

An ROC curve of 1 indicates a perfect prediction. In this study, all landslide sensitivity models were validated using success rate and a prediction rate method.

The success rate results were obtained by comparing landslide susceptibility maps with landslides in the training data set, while the prediction rate results for the susceptibility models were evaluated using the validation dataset independent of that used in the landslide model construction process and using the R software.

The ROC curves of this study are illustrated in Fig. 7.

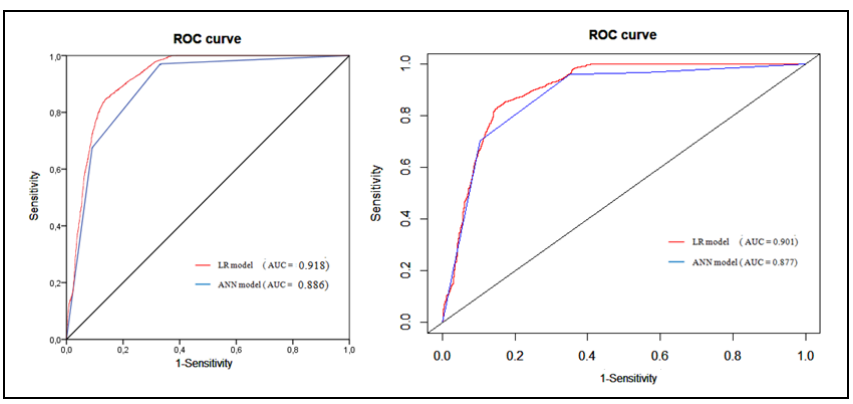

Fig. 7. ROC curve evaluation of the LR and ANN models : (a) success rate curves and (b) prediction rate curves.

The AUC values obtained from the susceptibility maps show that the LR model gave the highest success rate $(\mathrm{AUC}=0.918)$ and the best prediction rate $(\mathrm{AUC}=0.901)$ compared to the ANN model which has gave a low success rate AUC $=0.886$ and prediction rate $\mathrm{AUC}=0.877$.
These results indicate that the LR model is the best model for determining landslide sensitivity in the study area.

the landslide susceptibility maps were verified by landslides covering 4463 pixels of the municipality Oudka. These landslide were not used in the construction of the models. the landslide susceptibility maps of the three models were divided into five categories (Fig. 8) :

Very low $(0<$ LSI $\leq 0.2)$, Low $(0.2<$ LSI $\leq 0.4)$, medium $(0.4$ $<\mathrm{LSI} \leq 0.6)$, high $(0.6<\mathrm{LSI} \leq 0.8)$ and very high $(\mathrm{LSI}>0,8)$.

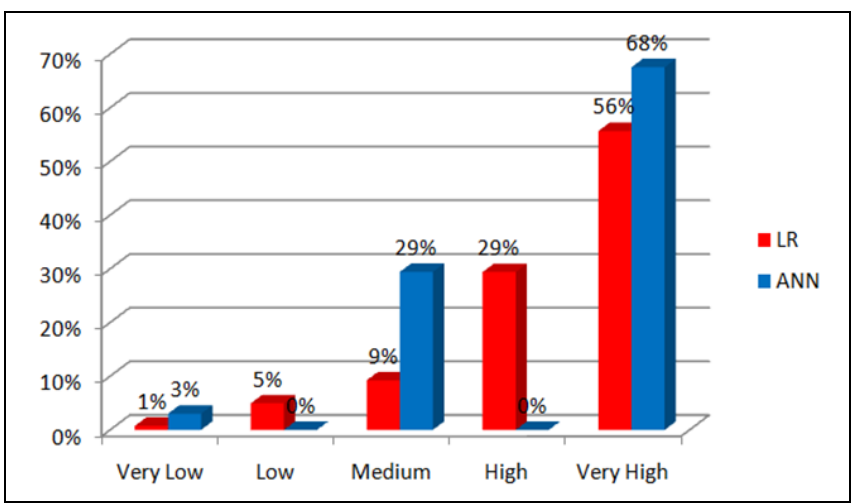

Fig. 8 : Percentages of test landslide points falling into different susceptibility categories using LR and ANN.

The superposition between the verification landslides (4463 pixels) and the landslide susceptibility maps resulting the LR and ANN models, allowed us to determine the Percentages of test landslide points falling into different susceptibility categories (Fig. 8):

in the very low susceptibility class, we found just $1 \%$ of the observed landslides for the LR methods, and 3\% for the ANN method. However, In the high and very high susceptibility classes, we found $85 \%$ and $68 \%$ of the landslide observed in these classes for the LR and ANN methods, respectively.

By comparing the results of the LR and ANN analysis, we determined that the LR method was better than the ANN method.

The LR method is the best approach for the assessment of landslide susceptibility for the commune of Oudka.

\section{DISCUSSION AND CONCLUSIONS}

The commune of the oudka is an extension of the Rif chain and is characterized by a mountainous terrain, containing a very important vegetation cover such as the Oudka forest.

the commune of the oudka is frequently subject to landslides. Recently, many landslides have occurred in this area, the largest is the landslide of Tissoufa, in northern Oudka, caused by the heavy rains of 2013 which caused the total demolition of five construction and cutting of the road RP 5302.

Field surveys, aerial photography interpretation and data analysis allowed for the identification of factors causing landslides.

In this study, the LR and ANN models were used to analyze landslide susceptibility and create landslide susceptibility maps useful to local authorities when choosing appropriate locations for implementing land use plans and environmental protection (Ozdemir and Altural, 2013). Based on the results of both models, we identified LR as the best model with the highest predictive power for the study area.

In any landslide susceptibility analysis, a level of susceptibility is assumed that an active landslide will occur. If only areas of high to very high susceptibility were at risk, LR would provide 
the best results. If landslides were found in areas with at least moderate susceptibility, the LR model would also yield better results. Lower percentages of landslides were observed in areas of low susceptibility.

\section{ACKNOWLEDGEMENTS (OPTIONAL)}

This work was made possible thanks to Taounate's DPELTE, the Moroccan Public Laboratory for Testing and Studies (LPEE), the Hydraulic Basin Agency of Fes..

\section{REFERENCES}

Akgun A. 2012. A comparison of landslide susceptibility maps produced by logistic regression, multi-criteria decision, and likelihood ratio methods: a case study at İzmir, Turkey. Landslides. 9:93-106.

Atkinson, P. M., and R. Massari. 2011. "Autologistic Modelling of Susceptibility to Landsliding in the Central Apennines, Italy." Geomorphology, Scale Issues in Geomorphology, 130 (1): 55-64. https://doi.org/10.1016/j.geomorph.2011.02.001.

Bai, Shi-Biao, Jian Wang, Guo-Nian Lü, Ping-Gen Zhou, Sheng-Shan Hou, and Su-Ning Xu. 2010. "GIS-Based Logistic Regression for Landslide Susceptibility Mapping of the Zhongxian Segment in the Three Gorges Area, China." Geomorphology $115 \quad$ (1): 23-31. https://doi.org/10.1016/j.geomorph.2009.09.025.

Bai, S. B., J. Wang, B. Thiebes, C. Cheng, and Z. Y. Chang. 2014. "Susceptibility Assessments of the Wenchuan Earthquake-Triggered Landslides in Longnan Using Logistic Regression.” Environmental Earth Sciences 71 (2): 731-743. https://doi.org/10.1007/s12665-013-2475-z.

Belsley, David A. 1991. "A Guide to Using the Collinearity Diagnostics." Computer Science in Economics and $\begin{array}{llll}\text { Management } & 4 & \text { (1): }\end{array}$ https://doi.org/10.1007/BF00426854.

Booth, G.D., M.J. Niccolucci, and E.G. Schuster. 1994. Identifying proxy sets in multiple linear regression: An aid to better coefficient interpretation. USDA. For. Serv. Res. Pap. INT-470.

Bui Dieu Tien, Biswajeet Pradhan, Owe Lofman , Inge Revhaug , Oystein B. Dick. "Landslide susceptibility assessment in the Hoa Binh province of Vietnam: A comparison of the Levenberg-Marquardt and Bayesian regularized neural networks." Geomorphology 171-172 (2012) 12-29.

Chung, Chang-jo F., and Andrea G. Fabbri. 1999. Probabilistic Prediction Models for Landslide Hazard Mapping. Photogrammetric Engineering and Remote Sensing,65(12): 1389-1399.

Das, Iswar, Sashikant Sahoo, Cees van Westen, Alfred Stein, and Robert Hack. 2010. "Landslide Susceptibility Assessment Using Logistic Regression and Its Comparison with a Rock Mass Classification System, along a Road Section in the Northern Himalayas (India).” Geomorphology 114 (4): 627637. https://doi.org/10.1016/j.geomorph.2009.09.023.
Demir, Gokhan, Mustafa Aytekin, and Aykut Akgun. 2015. "Landslide Susceptibility Mapping by Frequency Ratio and Logistic Regression Methods: An Example from NiksarResadiye (Tokat, Turkey)." Arabian Journal of Geosciences 8 (3): 1801-1812. https://doi.org/10.1007/s12517-014-1332-z.

Devkota KC, Regmi AD, Pourghasemi HR, Yoshida K, Pradhan B, Ryu IC, Dhital MR, Althuwaynee OF. 2013. Landslide susceptibility mapping using certainty factor, index of entropy and logistic regression models in GIS and their comparison at Mugling-Narayanghat road section in Nepal Himalaya. Nat Hazards. 65:135-165.

Dou J, Yamagishi H, Pourghasemi HR, Yunus AP, Song X, Xu Y, Zhu Z. 2015. An integrated artificial neural network model for the landslide susceptibility assessment of Osado Island, Japan. Nat Hazards. 78:1749-1776.

Fawcett, Tom. 2006. "An Introduction to ROC Analysis." Pattern Recognition Letters, ROC Analysis in Pattern $\begin{array}{llll}\text { Recognition, } & 27 & \text { (8): } & \text { 861-874. }\end{array}$ https://doi.org/10.1016/j.patrec.2005.10.010.

Hair JF, Black WC, Babin BJ, Anderson RE (2009) Multivariate data analysis. Prentice Hall, New York.

Hong H, Naghibi SA, Pourghasemi HR, Pradhan B. 2016a. GIS-based landslide spatial modeling in Ganzhou city, China. Arab J Geosci. 9(2):1-26.

Hong HY, Pradhan B, Xu C, Tien Bui D. 2015. Spatial prediction of landslide hazard at the Yihuang area (China) using two-class kernel logistic regression, alternating decision tree and support vector machines. Catena. 133:266-281.

Lee, Saro, Joo-Hyung Ryu, and Ii-Soo Kim. 2007. "Landslide Susceptibility Analysis and Its Verification Using Likelihood Ratio, Logistic Regression, and Artificial Neural Network Models: Case Study of Youngin, Korea." Landslides 4 (4): 327-338. https://doi.org/10.1007/s10346-007-0088-x.

Lee S, Pradhan B. 2007. Landslide hazard mapping at Selangor, Malaysia using frequency ratio and logistic regression models. Landslides. 4(1):33-41.

Liao D, Valliant R (2012) Variance inflation factors in the analysis of complex survey data. Surv Methodol 38:53-62.

Nandi, A., and A. Shakoor. 2010. "A GIS-Based Landslide Susceptibility Evaluation Using Bivariate and Multivariate Statistical Analyses.” Engineering Geology 110 (1): 11-20. https://doi.org/10.1016/j.enggeo.2009.10.001.

Nefeslioglu HA, Gokceoglu C, Sonmez H. 2008. An assessment on the use of logistic regression and artificial neural networks with different sampling strategies for the preparation of landslide susceptibility maps. Eng Geol. 97:171-191.

Nefeslioglu HA, Sezer E, Gokceoglu C, Bozkir AS, Duman TY. 2010. Assessment of landslide susceptibility by decision trees in the metropolitan area of Istanbul, Turkey. Math Prob Eng. 2010:1-15.

Nourani V, Pradhan B, Ghaffari H, Sharifi SS. 2014. Landslide susceptibility mapping at Zonouz Plain, Iran using genetic programming and comparison with frequency ratio, logistic 
regression, and artificial neural network models. Nat Hazards. 71:523-547.

Ozdemir Adnan and Tolga Altural.2013. "A comparative study of frequency ratio, weights of evidence and logistic regression methods for landslide susceptibility mapping: Sultan Mountains, SW Turkey." Journal of Asian Earth Sciences 64 (2013) 180-197.

Park S, Choi C, Kim B, Kim J. 2013. Landslide susceptibility mapping using frequency ratio, analytic hierarchy process, logistic regression, and artificial neural network methods at the Inje area, Korea. Environ Earth Sci. 68:1443-1464.

Peng L, Niu RQ, Huang B, Wu XL, Zhao YN, Ye RQ. 2014. Landslide susceptibility mapping based on rough set theory and support vector machines: a case of the Three Gorges area, China. Geomorphology. 204:287-301.

Pijanowski, Bryan C, Daniel G Brown, Bradley A Shellito, and Gaurav A Manik. 2002. "Using Neural Networks and GIS to Forecast Land Use Changes: A Land Transformation Model." Computers, Environment and Urban Systems 26 (6): 553-575. https://doi.org/10.1016/S0198-9715(01)00015-1.

Poudyal CP, Chang C, Oh HJ, Lee S. 2010. Landslide susceptibility maps comparing frequency ratio and artificial neural networks: a case study from the Nepal Himalaya. Environ Earth Sci. 61:1049-1064.

Pourghasemi HR, Mohammady M, Pradhan B. 2012a. Landslide susceptibility mapping using index of entropy and conditional probability models in GIS: Safarood Basin, Iran. Catena. 97:71-84.

Pourghasemi HR, Pradhan B, Gokceoglu C, Moezzi KD. 2012b. Landslide susceptibility mapping using a spatial multi criteria evaluation model at Haraz watershed, Iran. In: Pradhan $\mathrm{B}$, Buchroithner $\mathrm{M}$, editors. Terrigenous mass movements. Berlin Heidelberg: Springer- erlag; p. 23-49. doi:10.1007/9783-642-25495-6 2

Rumelhart, D. E., and J. L. Mcclelland. 1986. "Parallel Distributed Processing: Explorations in the Microstructure of Cognition. Volume 1. Foundations," January. https://www.osti.gov/biblio/5838709.

Schuerman J (1983) Principal components analysis. Multivariate analysis in the human services. Springer, Netherlands, pp 93-119.

Shahabi H, Hashim M, Ahmad BB. 2015. Remote sensing and GIS-based landslide susceptibility mapping using frequency ratio, logistic regression, and fuzzy logic methods at the central Zab Basin, Iran. Environ Earth Sci. 73:8647-8668.

Shahabi, Himan, Saeed Khezri, Baharin Bin Ahmad, and Mazlan Hashim. 2014. "Landslide Susceptibility Mapping at Central Zab Basin, Iran: A Comparison between Analytical Hierarchy Process, Frequency Ratio and Logistic Regression Models." CATENA 115 (April) : 55-70. https://doi.org/10.1016/j.catena.2013.11.014.

Sharma LP, Patel N, Ghose MK, Debnath P. 2013. Synergistic application of fuzzy logic and geo-informatics for landslide vulnerability zonation-a case study in Sikkim Himalayas, India. Appl Geomat. 5:271-284.

Soeters, Robert, Van Westen, and Cornelis J. 1996."landslides: investigation and mitigation. Chapter 8 - slope instability recognition, analysis, and zonation." Transportation Research Board Special Report, no. 247 (January). https://rid.trb.org/view/462506.

Song, Jae-Joon, Chung-In Lee, and Masahiro Seto. 2001. "Stability Analysis of Rock Blocks around a Tunnel Using a Statistical Joint Modeling Technique." Tunnelling and Underground Space Technology 16 (4): 341-351. https://doi.org/10.1016/S0886-7798(01)00063-3.

Tasoglu IK, Citiroglu HK, Mekik C (2016) GIS-based landslide susceptibility assessment: a case study in Kelemen Valley (Yenice- Karabuk, NW Turkey). Environ Earth Sci 75(18):1291. https://doi.org/10.1007/s12665-016-6098-z.

Tien Bui D, Pradhan B, Lofman O, Revhaug I. 2012. Landslide susceptibility assessment in Vietnam using support vector machines, decision tree, and Naive Bayes models. Math Probl Eng. 2012(2012), Article ID 974638, 26. http://dx.doi.org/10.1155/2012/974638

Tien Bui DT, Tuan TA, Klempe H, Pradhan B, Revhaug I. 2015. Spatial prediction models for shallow landslide hazards: a comparative assessment of the efficacy of support vector machines, artificial neural networks, kernel logistic regression, and logistic model tree. Landslides. doi:10.1007/s10346-0150557-6.

Umar Z, Pradhan B, Ahmad A, Jebur MN, Tehrany MS. 2014. Earthquake induced landslide susceptibility mapping using an integrated ensemble frequency ratio and logistic regression models in West Sumatera province, Indonesia. Catena. 118:124-135.

Van .Westen, C. J, N. Rengers, and R. Soeters. 2003. "Use of Geomorphological Information in Indirect Landslide Susceptibility Assessment." Natural Hazards 30 (3): 399-419. https://doi.org/10.1023/B:NHAZ.0000007097.42735.9e.

Xu C, Xu XW, Dai FC, Saraf AK. 2012b. Comparison of different models for susceptibility mapping of earthquake triggered landslides related with the 2008 Wenchuan earthquake in China. Comput Geosci. 46:317-329.

Yesilnacar, E., and T. Topal. 2005. "Landslide Susceptibility Mapping: A Comparison of Logistic Regression and Neural Networks Methods in a Medium Scale Study, Hendek Region (Turkey)." Engineering Geology 79 (3): 251-266. https://doi.org/10.1016/j.enggeo.2005.02.002.

Yilmaz I. 2010b. Comparison of landslide susceptibility mapping methodologies for Koyulhisar, Turkey: conditional probability, logistic regression, artificial neural networks, and support vector machine. Environ Earth Sci. 61:821-836.

Zare M, Pourghasemi HR, Vafakhah M, Pradhan B. 2013. Landslide susceptibility mapping at Vaz Watershed (Iran) using an artificial neural network model: a comparison between multilayer perceptron (MLP) and radial basic function (RBF) algorithms. Arab J Geosci. 6(8):2873-2888. 
Zhou, Weiyang. 1999. "Verification of the Nonparametric Characteristics of Backpropagation Neural Networks for Image Classification." IEEE Transactions on Geoscience and Remote Sensing 37 (2): 771-779. https://doi.org/10.1109/36.752193.

Zhu AX, Wang RX, Qiao JP, Qin CZ, Chen YB, Liu J, Du F, Lin Y, Zhu TX. 2014. An expert knowledge-based approach to landslide susceptibility mapping using GIS and fuzzy logic. Geomorphology. 214:128-138. 